\title{
Effects of diet fermentability and supplementation of 2-hydroxy- 4-(methylthio)-butanoic acid and isoacids on milk fat depression: 2. Ruminal fermentation, fatty acid, and bacterial community structure
}

\author{
C. Lee, ${ }^{1 *} \odot$ J. E. Copelin, ${ }^{1} \oplus$ T. Park, ${ }^{2} \odot$ K. E. Mitchell, ${ }^{2} \oplus$ J. L. Firkins, ${ }^{2} \odot$ M. T. Socha, ${ }^{3} \oplus$ and D. Luchini ${ }^{4} \odot$ \\ ${ }^{1}$ Department of Animal Sciences, Ohio Agricultural Research and Development Center, The Ohio State University, Wooster 44691 \\ ${ }^{2}$ Department of Animal Sciences, The Ohio State University, Columbus 43210 \\ ${ }^{3}$ Zinpro Corporation, Eden Prairie, MN 55344 \\ ${ }^{4}$ Adisseo, Alpharetta, GA 30022
}

\begin{abstract}
The experiment was conducted to understand ruminal effects of diet modification during moderate milk fat depression (MFD) and ruminal effects of 2-hydroxy4-(methylthio)-butanoic acid (HMTBa) and isoacids on alleviating MFD. Five ruminally cannulated cows were used in a $5 \times 5$ Latin square design with the following 5 dietary treatments (dry matter basis): a high-forage and low-starch control diet with $1.5 \%$ safflower oil (HF-C); a low-forage and high-starch control diet with $1.5 \%$ safflower oil (LF-C); the LF-C diet supplemented with HMTBa $(0.11 \% ; 28 \mathrm{~g} / \mathrm{d}$; LF-HMTBa); the LF-C diet supplemented with isoacids [(IA) $0.24 \% ; 60 \mathrm{~g} / \mathrm{d}$; LF-IA]; and the LF-C diet supplemented with HMTBa and IA (LF-COMB). The experiment consisted of 5 periods with $21 \mathrm{~d}$ per period (14-d diet adaptation and 7-d sampling). Ruminal samples were collected to determine fermentation characteristics $(0,1,3$, and 6 $\mathrm{h}$ after feeding), long-chain fatty acid (FA) profile (6 $\mathrm{h}$ after feeding), and bacterial community structure by analyzing $16 \mathrm{~S}$ gene amplicon sequences $(3 \mathrm{~h}$ after feeding). Data were analyzed using the MIXED procedure of SAS (SAS Institute Inc., Cary, NC) in a Latin square design. Preplanned comparisons between HF-C and LF-C were conducted, and the main effects of HM$\mathrm{TBa}$ and IA and their interaction within the LF diets were examined. The LF-C diet decreased ruminal $\mathrm{pH}$ and the ratio of acetate to propionate, with no major changes detected in ruminal FA profile compared with HF-C. The $\alpha$-diversity for LF-C was lower compared with HF-C, and $\beta$-diversity also differed between LF-C and HF-C. The relative abundance of bacterial phyla and genera associated indirectly with fiber degradation was influenced by LF-C versus HF-C. As the main ef-
\end{abstract}

Received May 24, 2020.

Accepted September 21, 2020.

*Corresponding author: lee.7502@osu.edu fect of HMTBa within the LF diets, HMTBa increased the ratio of acetate to propionate and butyrate molar proportion. Ruminal saturated FA were increased and unsaturated FA concentration were decreased by HMT$\mathrm{Ba}$, with minimal changes detected in ruminal bacterial diversity and community. As the main effect of IA, IA supplementation increased ruminal concentration of all branched-chain volatile FA and valerate and increased the percentage of trans-10 C18 isomers in total FA. In addition, $\alpha$-diversity and the number of functional features were increased for IA. Changes in the abundances of bacterial phyla and genera were minimal for IA. Interactions between HMTBa and IA were observed for ruminal variables and some bacterial taxa abundances. In conclusion, increasing diet fermentability (LF-C vs. HF-C) influenced rumen fermentation and bacterial community structure without major changes in FA profile. Supplementation of HMTBa increased biohydrogenation capacity, and supplemental IA increased bacterial diversity, possibly alleviating MFD. The combination of HMTBa and IA had no associative effects in the rumen and need further studies to understand the interactive mechanism.

Key words: high-concentrate diet, methionine analog, branched-chain volatile fatty acids, valerate

\section{INTRODUCTION}

Milk fat depression (MFD) can be easily induced with diet modification (Jenkins and Harvatine, 2014) and is an economic loss for dairy producers. When diet fermentability and PUFA content increase, severe MFD can occur (Rico and Harvatine, 2013; Jenkins and Harvatine, 2014; Rico et al., 2014) where production of trans-10 C18 isomers through increased alternate biohydrogenation was the main cause of MFD. Therefore, the term of classic diet-induced or biohydrogenationinduced MFD has been used to explain severe MFD occurring when diet fermentation and PUFA content increased. A change in VFA profile (e.g., acetate and 
propionate) was initially considered another factor for MFD, but this explains only a small part of MFD (Jenkins and Harvatine, 2014). However, although changes in alternate biohydrogenation intermediates have been considered the major factor for severe MFD, this also does not fully explain MFD occurring by dietary changes (Dewanckele et al., 2020), suggesting a variety of unknown factors causing MFD. Limited information is available about the mechanism of moderate MFD, assuming that moderate MFD often occurs in commercial farms due to animal variations (Baldin et al., 2018b) and the relatively low PUFA content in rations (e.g., commercial fat supplements are mostly SFA or MUFA).

Supplementing a diet with 2-hydroxy-4-(methylthio)butanoic acid (HMTBa) often increased milk fat yield according to a meta-analysis by Zanton et al. (2014). Baldin et al. (2018b) and Pitta et al. (2020) observed alleviation of MFD when HMTBa was fed, including changes in ruminal bacterial community composition. Isoacids (IA) refer to isobutyrate, isovalerate, 2-methylbutyrate, and valerate, and improve growth or activity of ruminal bacteria, especially cellulolytics (Dehority et al., 1967; Andries et al., 1987). Branched-chain VFA (BCVFA; isoacids without the straight chain, valerate) are required by microbes to synthesize branched-chain amino acids (BCAA) or branched long-chain fatty acids (FA; cell membrane constituent; Allison et al., 1962; Maczulak et al., 1981). In addition, supplementation with IA often increased fiber digestibility and milk fat yield (Peirce-Sandner et al., 1985; Wang et al., 2019). Butyrivibrio proteoclasticus, the major characterized stearate producer, was hypothesized to be very susceptible to inhibition by free PUFA and was recognized for very high C16:0 iso (derived from isobutyrate) and C17:0 anteiso (derived from 2-methylbutyrate) composition of its membranes (Hackmann and Firkins, 2015). Therefore, IA could be another potential feed additive to alleviate MFD. The potential effects of HMTBa and IA on milk fat suggest that the combination may have a synergistic effect, further alleviating risk of MFD compared with supplementation of HMTBa or IA alone.

We hypothesized that a diet with increased fermentability alters ruminal fermentation and FA profile by shifting bacterial diversity and community, but supplementation of HMTBa or IA would improve resiliency of ruminal bacteria to help maintain ruminal FA profile with lower trans-10 $\mathrm{C} 18$ isomers. In addition, the combination of HMTBa and IA was proposed to have an additive effect to changes in ruminal variables, FA profile, and bacterial community. The objective of the experiment was to determine factors for moderate MFD under different dietary conditions according to ruminal fermentation, FA profile, and bacterial diversity and community structure.

\section{MATERIALS AND METHODS}

\section{Animals, Diets, and Experimental Design}

The experiment was performed at Krauss Dairy Research Center at Agricultural Research and Development Center, The Ohio State University (Wooster). All procedures involving animals and their care were approved (2018A00000116) by the Institutional Animal Care and Use Committee of The Ohio State University.

This experiment was part of a larger study with a total of 10 multiparous lactating Holstein cows (mean \pm SD: $194 \pm 58$ DIM, $691 \pm 69 \mathrm{~kg} \mathrm{BW}$, and $28 \pm 5 \mathrm{~kg} / \mathrm{d}$ milk yield) in a replicated $5 \times 5$ Latin square design. Data presented in the study were produced only from cannulated cows (i.e., one square; nonreplicated Latin square design; $238 \pm 69$ DIM, $702 \pm 86 \mathrm{~kg} \mathrm{BW}$, and 24 $\pm 5 \mathrm{~kg} / \mathrm{d}$ milk yield) with a focus on ruminal effects on MFD. Production, milk FA profile, and nutrient digestibility were determined from all cows and presented in our companion paper (Copelin et al., 2021). The experiment consisted of 5 periods with $21 \mathrm{~d}$ per period (14 d for adaptation and $7 \mathrm{~d}$ for sampling).

Details about diet ingredients and chemical composition are presented in our companion paper (Copelin et al., 2021). Briefly, dietary treatments (DM basis) included a relatively high-forage and low-starch diet with $1.5 \%$ safflower oil (24\% starch, $32 \%$ NDF, and $3.4 \%$ total FA; positive control; HF-C), a relatively low-forage and high-starch diet with $1.5 \%$ safflower oil (29\% starch, 29\% NDF, and 3.5\% total FA; negative control; LF-C), the LF-C diet supplemented with $0.11 \%$ of HMTBa in dietary DM (28 g/d; Adisseo, Antony, France; LF-HMTBa), the LF-C diet supplemented with $0.24 \%$ of IA in dietary DM (Zinpro Corp., Eden Prairie, MN) supplying about $0.24 \%$ of IA in dietary DM $(17 \mathrm{~g} / \mathrm{d}$ of isobutyrate, $17 \mathrm{~g} / \mathrm{d}$ of 2-methylbutyrate, $12 \mathrm{~g} / \mathrm{d}$ of isovalerate, and $14 \mathrm{~g} / \mathrm{d}$ of valerate; LF-IA), and the LF-C diet supplemented with the combination of HMTBa and IA (LF-COMB). All diets included safflower oil (70\% linoleic acid; Jedwards International Inc., Braintree, MA) at $1.5 \%$ in dietary DM to provide linoleic acid (37\% of linoleic acid in total dietary FA) as the main source of PUFA. Diets were formulated to meet or exceed the requirement of all nutrients for cows of $24 \mathrm{~kg} / \mathrm{d}$ DMI, $35 \mathrm{~kg} / \mathrm{d}$ milk yield, and $700 \mathrm{~kg} \mathrm{BW}$ according to NRC (2001). The supplements of HMTBa and IA were mixed with concentrates, and then the concentrates were mixed with forages and fed as a TMR for ad libitum intake with refusal targeted at 5 to 
$10 \%$ with free access to water. Cows were milked daily at $0400 \mathrm{~h}$ and $1700 \mathrm{~h}$.

\section{Sampling Procedures}

Whole rumen contents were collected from individual cannulated cows $(\mathrm{n}=5)$ at $0,1,3$, and $6 \mathrm{~h}$ after feeding on $\mathrm{d} 16$ and 17 . Whole rumen contents were taken from 5 different locations in the rumen (cranial dorsal, cranial ventral, central, caudal dorsal, and caudal ventral) and mixed thoroughly. The whole rumen contents were strained through 2 layers of a mesh screen $(0.5 \mathrm{~mm})$ and measured immediately for $\mathrm{pH}$ (AE150 $\mathrm{pH}$ Benchtop meter; Thermo Fisher Scientific, Waltham, MA). Subsamples of ruminal fluid were preserved with 0.5 $M \mathrm{H}_{2} \mathrm{SO}_{4}$ or $25 \%$ meta-phosphoric acid. The individual preserved samples were frozen at $-20^{\circ} \mathrm{C}$ and thawed to make a composite by cow and period before analyses for ammonia and VFA, respectively. Additional whole rumen contents collected at 3 and $6 \mathrm{~h}$ after feeding on d 16 and 17 were composited by cow, time point, and period. The composite samples collected at $3 \mathrm{~h}$ after feeding were stored at $-80^{\circ} \mathrm{C}$ and later determined for bacterial community analysis. The sampling time point (3 $\mathrm{h}$ after feeding) was chosen because we assumed that this was the time when ruminal bacterial activity and diversity for fermentation (biohydrogenation) is highest during a day (once-daily feeding). Ruminal bacterial mass and diversity likely have small diurnal variation (Li et al., 2009; van Lingen et al., 2017). However, van Lingen et al. (2017) found small increases in some bacterial genera in early time after feeding (within $4 \mathrm{~h}$ ) and considerable changes in ruminal metabolites (VFA) and gas emissions within $3 \mathrm{~h}$ after feeding. Whole rumen contents collected at $6 \mathrm{~h}$ after feeding were analyzed for FA profile. To justify the time point, Baldin et al. (2018a) showed that a bolus supply of oleic, linoleic, and linolenic acids increased most biohydrogenation intermediates up to 2 to $3 \mathrm{~h}$ and then decreased until $6 \mathrm{~h}$ after the dose, except that trans-11 C18:1 still remained relatively high in the rumen at $6 \mathrm{~h}$ after the dose. Because we provided PUFA through the diet instead of through a bolus dose (i.e., introduction of PUFA in the rumen at every meal), samples for FA profile were collected at $6 \mathrm{~h}$ after feeding.

\section{Laboratory Analyses}

To determine concentrations of ruminal fermentation end products, samples of rumen fluid were centrifuged at $12,000 \times g$ at $4^{\circ} \mathrm{C}$ for $10 \mathrm{~min}$, and supernatants were collected and analyzed for ammonia (Chaney and Marbach, 1962). Samples of rumen fluid for VFA analy- sis were centrifuged at $5,000 \times g$ at $4^{\circ} \mathrm{C}$ for $15 \mathrm{~min}$. The supernatants were processed according to Erwin et al. (1961), except that, after pivalic acid was added as the internal standard (Sigma-Aldrich, St. Louis, MO), samples were frozen at $-20^{\circ} \mathrm{C}$, thawed, and recentrifuged repeatedly until there was no precipitate. Total VFA concentration and VFA profile were determined using a Hewlett-Packard 5890 series gas chromatograph (Agilent Technologies, Santa Clara, CA) equipped with a glass packed column (23110-U, Sigma-Aldrich) with $\mathrm{N}_{2}$ as a carrier gas $(24 \mathrm{~mL} / \mathrm{min})$. The inlet was $150^{\circ} \mathrm{C}$, the flame ionization detector was $180^{\circ} \mathrm{C}$, and the oven temperature was $175^{\circ} \mathrm{C}$. Each run was 18 min long to separate acetate (retention time: $1.6 \mathrm{~min}$ ), propionate (3.0 $\mathrm{min})$, isobutyrate $(5.2 \mathrm{~min})$, butyrate $(6.8 \mathrm{~min})$, pivalic acid (internal standard; $7.8 \mathrm{~min}$ ), 2-methylbutyrate $(11 \mathrm{~min})$, isovalerate $(12.9 \mathrm{~min})$, and valerate (16.1 min). Between each injection a sample of distilled $\mathrm{H}_{2} \mathrm{O}$ was injected and run through the same conditions to prevent carryover between samples.

Freeze-dried and ground ruminal samples were methylated according to the 2-step procedure described by Jenkins (2010) with nonadecanoic acid (C19:0, NuChek Prep, Elysian, MN) as an internal standard, and then quantified by GLC analysis. Separation of FAME was performed with a CPSil 88 column $(100-\mathrm{m} \times 0.25$ $\mathrm{mm}$ internal diameter, $0.2-\mu \mathrm{m}$ film thickness; Varian Inc., Palo Alto, CA). The column methodology is to start at $100^{\circ} \mathrm{C}$ and hold for $2 \mathrm{~min}$, then heat up to $170^{\circ} \mathrm{C}$ by $6^{\circ} \mathrm{C}$ per min (held for $50 \mathrm{~min}$ ), and then, in the final stage, heat to $220^{\circ} \mathrm{C}$ by $8^{\circ} \mathrm{C}$ per min (held for $20 \mathrm{~min}$ ). Hydrogen was used as the column carrier gas, and the temperatures of the injector and detector were $250^{\circ} \mathrm{C}$ and $255^{\circ} \mathrm{C}$, respectively. Methyl esters were identified with a flame ionization detector based on retention time of known standards (trans and cis C18 isomers, Matreya LLC, State College, PA; Mixture BR 2, Larodan, Monroe, MI; GLC-60 and GLC-68D, $\mathrm{Nu}-$ Chek Prep).

Whole rumen contents were thawed, and DNA was extracted using the repeated bead beating plus column method (Yu and Morrison, 2004). The nucleic acids were purified before sequencing using the QIAamp DNA Stool Mini Kit protocol (Qiagen Inc., Valencia, CA). All samples were normalized to $5 \mathrm{ng} / \mu \mathrm{l}$ and sequenced by the Molecular and Cellular Imaging Center (The Ohio State University, Ohio Agricultural and Research and Development Center, Wooster) with Illumina sequencing by MiSeq platform (Illumina Inc., San Diego, CA). This was performed using reagent kit V3 with $2 \times 300$-bp pair-ended sequencing. The V4-V5 hypervariable region of the $16 \mathrm{~S}$ rRNA gene was targeted to analyze the ruminal prokaryotic community with a 
universal primer (515F 5'-GTGYCAGCMGCCGCGGTAA-3 and 806R 5'-GGACTACNVGGGTWTCTAAT-3') and 300-bp pair-ended approach (Caporaso et al., 2010). Raw sequencing reads deposited in the NCBI Sequencing Read Archive can be downloaded via accession number BioProject PRJNA625341. The amplicon sequences were analyzed using the plugins builtin QIIME2 (version 2019.10; Bolyen et al., 2019). First, Cutadapt was used to remove adapter and primer sequences from the raw sequencing reads (Martin, 2011). Then, for denoising, merging, and chimeric sequence removal, the DADA2 plugin was used (Callahan et al., 2016) following quality filtering (Q-score $>25$; Supplemental Table S1, https://datadryad.org/stash/dataset/ doi:10.5061/dryad.zcrjdfn99). Further taxonomic-based filtering was done to remove the sequences assigned to "unassigned," "mitochondria," and "chloroplast." With amplicon sequencing variants (ASV) clustered at $99 \%$ similarity, taxonomic classification was performed using pre-trained classifiers for our primer sequences from Silva 16S reference database (NR 132 version; Quast et al., 2013). The genera present in more than $50 \%$ of the samples and their corresponding phyla were presented and mainly discussed throughout the manuscript.

Alpha-diversity indices incorporating species richness (observed ASV and Chao1 estimates), Pielou's evenness, Faith's phylogenetic diversity, and Shannon's index were derived based on the rarefied ASV BIOM Tables $(6,844$ randomly selected sequences per sample; https://forum.qiime2.org/t/alpha-and-beta-diversity -explanations-and-commands/2282). Principal coordinates analyses based on both the unweighted (presence or absence of observed ASV) and weighted (accounting for the abundance of observed ASV) UniFrac distance matrices were computed to compare overall microbial communities between treatments. Based on the denoised ASV from each sample, Phylogenetic Investigation of Communities by Reconstruction of Unobserved States 2 (PICRUSt2) was used to predict 7 different functional features [G. M. Douglas (Dalhousie University, Halifax, NS, Canada), V. J. Maffei (Louisiana State University, New Orleans), J. Zaneveld (University of Washington, Seattle), S. N. Yurgel (Dalhousie University, Truro, NS, Canada), J. R. Brown (GlaxoSmithKline R\&D, Collegeville, PA), C. M. Taylor (Louisiana State University, New Orleans), C. Huttenhower (Harvard T. H. Chan School of Public Health, Boston, MA), and M. G. Langille (Dalhousie University, Halifax, Nova Scotia, Canada), unpublished data; Supplemental Table S2, https://datadryad.org/stash/dataset/doi:10.5061/ dryad.zcrjdfn99] using the implemented reference databases in PICRUSt2.

\section{Statistical Analysis}

Data of ruminal bacterial profile, $\alpha$-diversity, and functional features were analyzed in a Latin square design using the MIXED procedure of SAS (SAS 9.4; SAS Institute Inc., Cary, NC). The mixed model included the fixed effects of treatment and period and random effect of cow. For ruminal fermentation, hour, and treatment by hour interaction were included in the model and analyzed using repeated measures with $\mathrm{AR}(1)$ as the covariance structure according to lowest Akaike information criterion. Treatment and hour interactions for all variables were $P>0.10$ and not shown in tables. Preplanned contrasts were used to determine the difference between HF-C and LF-C. The main effect of HMTBa (LF-HMTBa and LF-COMB vs. LF-C and LF-IA), IA (LF-IA and LF-COMB vs. LF-C and LF-HMTBa), and the interaction between HMTBa and IA were tested within the LF diets. Therefore, effects of HMTBa and IA are referred to as the main effects of HMTBa and IA, respectively. Permutational multivariate ANOVA was computed to analyze the difference in microbial communities between treatments using PAST3 (Hammer et al., 2001) with 9,999 random permutations. Statistical differences were declared at $P$ $\leq 0.05$. Differences between treatments with $0.05<P$ $\leq 0.10$ were considered as trends toward significance.

\section{RESULTS}

\section{Rumen Fermentation Characteristics}

The LF-C diet decreased overall ruminal $\mathrm{pH}(P=$ $0.01)$ and $\mathrm{NH}_{3}$ concentration $(P=0.02)$ compared with HF-C (Table 1). However, total VFA concentration did not differ between LF-C and HF-C. In VFA composition, molar percentage of acetate in total VFA decreased $(P=0.01)$ and that of propionate increased $(P<0.01)$, which decreased the acetate:propionate ratio $(P<0.01)$ for LF-C compared with HF-C. In addition, LF-C increased (1.27 vs. $0.85 \% ; P<0.01)$ molar percentage of 2-methylbutyrate compared with $\mathrm{HF}$. Supplementation of IA tended to increase $(P=0.07$ for main effect) $\mathrm{NH}_{3}$, but HMTBa and IA interacted $(P=0.01)$. Supplemental HMTBa and IA decreased $(P=0.05)$ or tended to decrease $(P=0.08)$ propionate molar percentage, respectively. Butyrate was increased as well $(P \leq 0.03)$ by HMTBa and IA supplementation, but an interaction $(P=0.03)$ between HMTBa and IA was observed. Supplementation of IA increased $(P \leq$ 0.04) all BCVFA, but did not increase valerate within the LF diets. However, interactions between HMTBa 
and IA for 2-methylbutyrate and valerate $(P \leq 0.07)$ were observed. Ruminal $\mathrm{pH}$ and total VFA were not affected by HMTBa or IA.

\section{Rumen Fatty Acid Profile}

Ruminal FA profiles did not show major differences between LF-C versus HF-C (Table 2). Therefore, LF-C did not alter total odd- and branched-chain FA and total saturated, monounsaturated, and polyunsaturated FA. However, supplementation of HMTBa within the $\mathrm{LF}$ diets (i.e., the main effect of HMTBa) decreased $(P=0.01)$ the concentration of $\mathrm{C} 16: 0$ but increased $(P=0.04)$ C18:0. In addition, various trans and cis C18:1 FA were or tended to be lower $(P \leq 0.09)$ for HMTBa supplementation. The concentration of linoleic acid (cis-9,cis-12 C18:2) tended to be lower (14.7 vs. $17.0 \% ; P=0.06)$ for HMTBa supplementation. However, trans-10 C18:1 and any iso and anteiso FA were not affected by HMTBa. Therefore, HMTBa increased total concentration of saturated FA but decreased $(P$ $=0.05)$ unsaturated FA. Supplementation of IA within the LF diets (i.e, the main effect of IA) decreased $(P \leq$ 0.05) C13:0 anteiso and C16:0 iso. The concentration of C16:0 tended to be lower $(P=0.08)$ for IA supplementation, but C18:0 was not affected. Supplementation of IA did not affect trans-11 C18:1 but increased $(P=$ 0.05) trans-10 C18:1. In addition, cis-9, trans-11 C18:2 was lower $(P=0.02)$, but trans-10, cis-12 C18:2 tended to be greater $(P=0.06)$ for IA supplementation. The concentration of linoleic acid was not affected by IA supplementation. No interaction was detected for major ruminal FA between HMTBa and IA.

\section{Bacterial Diversity, Functional Features, and Community Structure}

Ruminal bacterial $\alpha$-diversity without (ASV and Chao1) and with considering bacterial abundance (Shannon's and Simpson's indices) indicates that LF-C had lower bacterial diversity $(P \leq 0.04)$ compared with HF-C (Table 3). Supplementation of HMTBa within the LF diets (i.e., the main effect of HMTBa) had no effect on bacterial diversity. However, IA supplementation within the LF diets (i.e., the main effect of IA) increased $(P<0.02)$ ruminal bacterial diversity, except that Simpson's index showed no main effect of IA $(P=0.58)$. No interaction between HMTBa and IA was observed for $\alpha$-diversity indices. Beta-diversity (weighted and unweighted) indicated that a group-togroup difference in bacterial community composition was found only between LF-C and HF-C (Table 4). Although bacterial diversity was lower for LF-C versus HF-C, the number of predicted bacterial functional features (Supplemental Table S2, https://datadryad .org/stash/dataset/doi:10.5061/dryad.zcrjdfn99) did not differ, and the main effect of IA within the LF diets increased $(P \leq 0.06)$ the number of bacterial func-

Table 1. Effects of diet fermentability and supplementation of 2-hydroxy-4-(methylthio)-butanoic acid (HMTBa) and isoacids (IA) on ruminal fermentation characteristics in lactating cows $(\mathrm{n}=5)$ fed a diet inducing milk fat depression

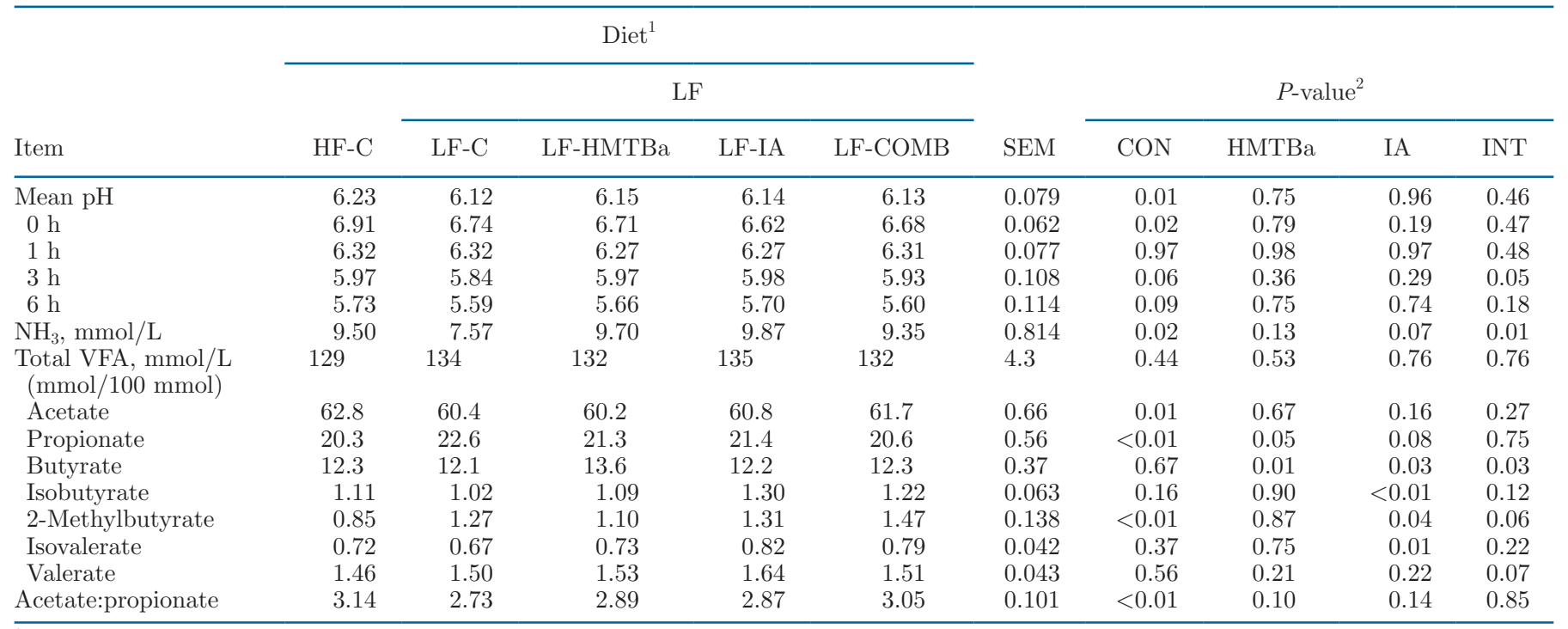

${ }^{1} \mathrm{HF}-\mathrm{C}=$ high-forage and low-starch diet; LF = low-forage and high-starch diet; LF-C = low-forage and high-starch diet with no supplementation; LF-HMTBa = LF-C diet supplemented with HMTBa; LF-IA = LF-C diet supplemented with IA; LF-COMB = LF-C diet supplemented with HMTBa and IA.

${ }^{2} \mathrm{CON}=\mathrm{HF}-\mathrm{C}$ vs. LF-C; HMTBa $=$ main effect of HMTBa in the LF diets; IA = main effect of IA in the LF diets; INT = interaction of HMTBa with IA. 
Table 2. Effects of diet fermentability and supplementing a diet inducing milk fat depression with 2-hydroxy-4-(methylthio)-butanoic acid (HMTBa) and isoacids (IA) on rumen fatty acid (FA) profile at $6 \mathrm{~h}$ after feeding

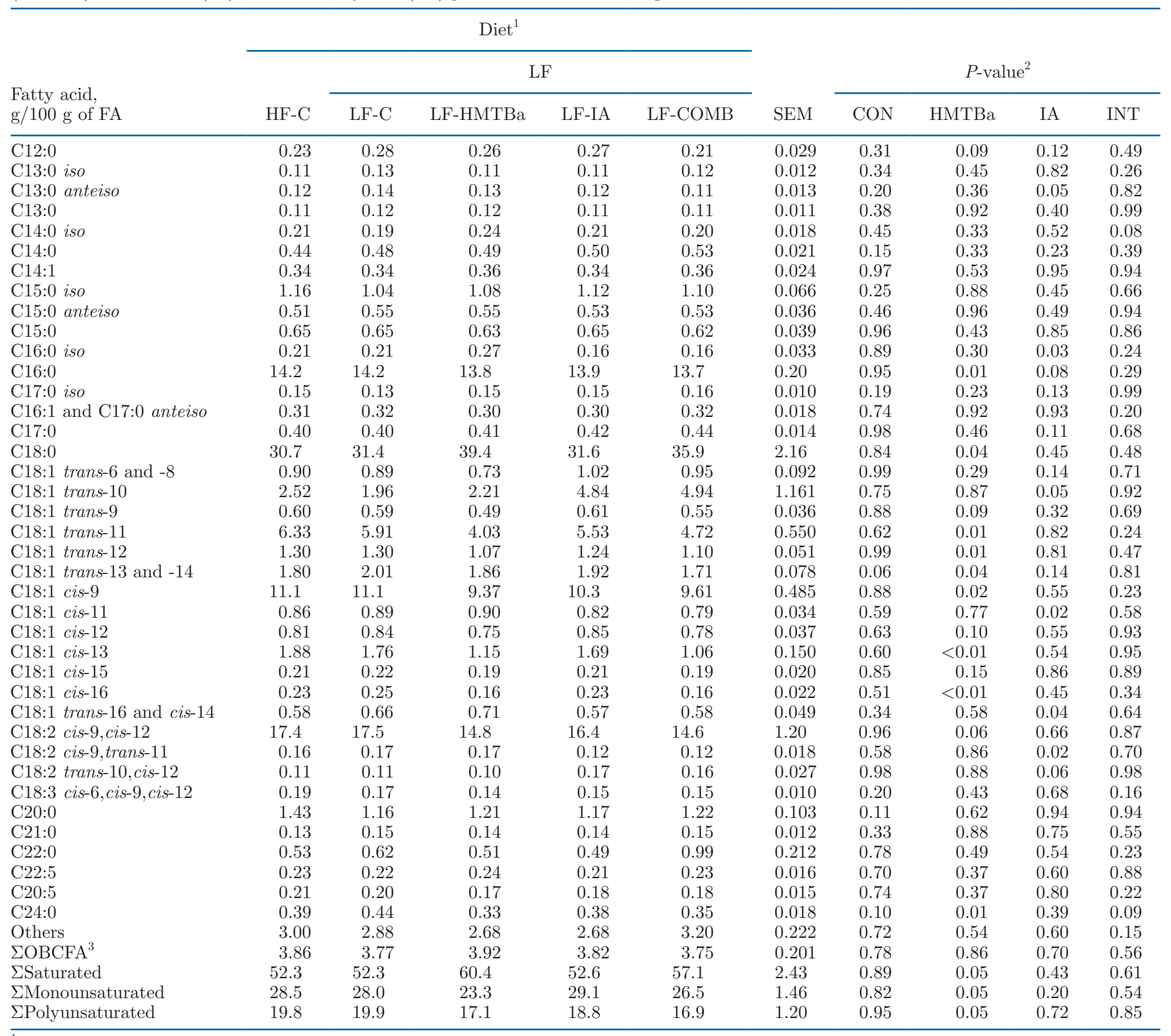

${ }^{1} \mathrm{HF}-\mathrm{C}=$ high-forage and low-starch diet; LF = low-forage and high-starch diet; LF-C = low-forage and high-starch diet with no supplementation; LF-HMTBa = LF-C diet supplemented with HMTBa; LF-IA = LF-C diet supplemented with IA; LF-COMB = LF-C diet supplemented with HMTBa and IA.

${ }^{2} \mathrm{CON}=\mathrm{HF}-\mathrm{C}$ vs. LF-C; HMTBa = main effect of HMTBa in the LF diets; IA = main effect of IA in the LF diets; INT = interaction of HMTBa with IA.

${ }^{3}$ Sum of all odd- and branched-chain fatty acids.

tional features, whereas no main effect of HMTBa was observed. Although data of functional features were different between treatments, the data table is left as a supplemental table because there are technical limitations of the amplicon sequencing approach (e.g., poorly detect rare taxa, primer and PCR bias, and others) as well as limited available reference database to correctly infer the genomic content of ruminal microbiota.

Relative abundances of ruminal bacterial taxa are shown in Table 5 at phylum and genus taxonomic levels. The major phyla observed were Bacteroidetes and Firmicutes, whose abundance did not differ between 
HF-C and LF-C. However, LF-C had lower relative sequence abundances of Spirochaetes, Verrucomicrobia $(P$ $\leq 0.02)$, and Planctomycetes $(P=0.07)$ but had greater abundances of Proteobacteria $(P=0.07)$ and TM7 $(P$ $<0.01)$ compared with HF-C. Supplementation of HMTBa within the LF diets had a minimal effect but increased $(P<0.01)$ Spirochaetes. Supplementation of IA within the LF diets also had no main effect on relative abundances of members at phylum levels, except that TM7 was lower $(P=0.02)$ in abundance. Interactions between HMTBa and IA were observed $(P \leq 0.09)$ for Tenericutes, Proteobacteria, TM7, and Verrucomicrobia. At the genus level, changes in the abundances by treatments were linked with changes in the abundances at phylum level by treatments. Interactions between HMTBa and IA within the LF diets were observed $(P \leq 0.09)$ for some bacterial phyla (Tenericutes, Proteobacteria, TM7, and Verrucomicrobia) and genera [Clostridium, Succiniclasticum, RF39_unclassified (UN), Coprococcus, F16_UN, RFP12_UN, p-75-a5, and RFN20].

\section{DISCUSSION}

The current experiment is part of a larger study (Copelin et al., 2021). The main focus of the larger study (10 cows with 2 squares in a replicated Latin square design) was DMI, production, milk FA profile, $\mathrm{N}$ balance, and nutrient digestibility. Briefly, HF-C, LF-C, LF-HMTBa, LF-IA, and LF-COMB had 3.38, $2.97,3.27,3.41$, and $3.23 \%$ of milk fat content and $0.98,0.87,1.00,1.01$, and $0.96 \mathrm{~kg} / \mathrm{d}$ of milk fat yield, respectively. The concentrations of milk trans-10,cis-12 C18:2 were low $(<0.03 \%)$ for all treatments, and the concentrations of milk trans-10 C18:1 were 1.52, 1.87, $1.55,1.65$, and $2.06 \%$ for HF-C, LF-C, LF-HMTBa, LF-IA, and LF-COMB, respectively. Feeding the LF-C diet decreased milk fat yield $(P<0.01)$ compared with HF-C; those supplemented with HMTBa or IA within the $4 \mathrm{LF}$ diets alleviated MFD $(P \leq 0.01)$ that was caused by LF-C. However, these effects were not additive for LF-COMB, causing an interaction of HMTBa by IA. In the current study, the purpose was to focus on ruminal effects of LF-C and effects of HMTBa and IA within the LF diets to explain moderate MFD (5 cannulated cows with 1 square in a Latin square design). Because no interactions of treatment by square for production (when square was tested as a fixed effect), rumen data in the current study were discussed in relation with production observed in our companion study. It is worth noting that 5 observations per treatment were used to obtain data of rumen fermentation and FA profile, and bacterial community structure and 
Table 4. Effects of diet fermentability and supplementation of 2-hydroxy-4-(methylthio)-butanoic acid (HMTBa) and isoacids (IA) on rumen bacterial $\beta$-diversity in lactating cows $(\mathrm{n}=5)$ fed a diet inducing milk fat depression ${ }^{1}$

\begin{tabular}{|c|c|c|c|c|c|}
\hline Item & HF-C & LF-C & LF-HMTBa & LF-IA & LF-COMB \\
\hline \multicolumn{6}{|c|}{$\begin{array}{l}\text { Unweighted } \\
\text { (PERMANOVA, }{ }^{2} P \text {-values) }\end{array}$} \\
\hline $\mathrm{HF}-\mathrm{C}$ & 1 & & & & \\
\hline LF-C & 0.012 & 1 & & & \\
\hline LF-HMTBa & 0.103 & 0.423 & 1 & & \\
\hline LF-IA & 0.252 & 0.318 & 0.686 & 1 & \\
\hline LF-COMB & 0.319 & 0.164 & 0.460 & 0.745 & 1 \\
\hline \multicolumn{6}{|c|}{$\begin{array}{l}\text { Weighted } \\
\text { (PERMANOVA, } P \text {-values) }\end{array}$} \\
\hline HF-C & 1 & & & & \\
\hline LF-C & 0.076 & 1 & & & \\
\hline LF-HMTBa & 0.200 & 0.342 & 1 & & \\
\hline LF-IA & 0.596 & 0.425 & 0.511 & 1 & \\
\hline LF-COMB & 0.141 & 0.599 & 0.763 & 0.767 & 1 \\
\hline
\end{tabular}

${ }^{1} \mathrm{HF}-\mathrm{C}=$ high-forage and low-starch diet; LF-C = low-forage and high-starch diet with no supplementation; LF-HMTBa = LF-C diet supplemented with HMTBa; LF-IA = LF-C diet supplemented with IA; LF-COMB $=$ LF-C diet supplemented with HMTBa and IA.

${ }^{2}$ Permutational multivariate ANOVA.

further experiments with larger numbers of cows may be necessary to confirm our results.

\section{Effects of Feeding LF-C Versus HF-C}

Changes of ruminal fermentation patterns observed for $\mathrm{LF}-\mathrm{C}$ versus HF-C were typical; that is, a decrease in $\mathrm{pH}$ and decrease in the ratio of acetate to propionate (Sánchez-Duarte et al., 2019). A decrease in ammonia concentration for LF-C versus HF-C was observed and could be a result of either increased microbial utilization or decreased dietary protein breakdown. In a continuous culture by Fuentes et al. (2009), decreased flows of $\mathrm{NH}_{3}-\mathrm{N}$ and bacterial $\mathrm{N}$ and increased dietary $\mathrm{N}$ flow were observed for low $\mathrm{pH}$ versus high $\mathrm{pH}$, suggesting reduced deamination of protein at low $\mathrm{pH}$. Other fermentation variables were not affected by LF-C versus HF-C, except 2-methylbutyrate (molar percentage). When rumen samples are analyzed for VFA using gas chromatography, 2-methylbutyrate usually co-elutes with isovalerate and the co-elution is usually published as isovalerate or isovalerate +2 -methylbutrate (RomanGarcia et al., 2016). Therefore, limited information is available in the literature about how 2-methylbutyrate is affected by diet fermentability. Ruminal concentration of 2-methylbutyrate is produced from Ile degradation and is required by major characterized cellulolytic bacteria (Andries et al., 1987). An increase in 2-methylbutyrate resulted from either increased Ile degradation or else reduced utilization of 2-methylbutyrate by rumen microbes. According to feed AA composition in NRC (2001), dietary Ile concentration was similar (4.1\% of $\mathrm{CP}$ ) between LF-C and HF-C, and therefore microbial utilization of 2-methylbutyrate was likely reduced. This might be supported with a 3 percentage-unit decrease $(P=0.12)$ in total-tract NDF digestibility for LF-C versus HF-C shown in our companion study (Copelin et al., 2021). However, relative abundances of Fibrobacter and Ruminococcus (culturable cellulolytics) were not affected. The decrease in $\alpha$-diversity for LF-C compared with HF-C and changes in $\beta$-diversity between LF-C and HF-C agrees with previous studies (AlZahal et al., 2017; Pitta et al., 2020). Interestingly, despite changes in $\alpha$-diversity and $\beta$-diversity, the number of bacterial functional features was not affected by LF-C versus HF-C (Supplemental Table S2, https://datadryad .org/stash/dataset/doi:10.5061/dryad.zcrjdfn99). The relative abundances of members within Spirochaetes was decreased and mostly explained by Treponema and Sphaerochaeta. Treponema spp. are noncellulolytic but support cellulolytic bacteria for fiber degradation (Stanton and Canale-Parola, 1980; Kudo et al., 1987), and the abundance of Treponema spp. in the rumen increased when dietary fiber content increased (Piao et al., 2014; Deusch et al., 2017). The abundance of Sphaerochaeta attached to feed particles also decreased quadratically when proportion of concentrate increased in a ration (Klevenhusen et al., 2017). In the current study, however, fiber-degrading bacteria (e.g., Fibrobacter and Butyrivibrio) were not affected for LF-C versus HF-C, and Ruminococcus was actually increased for LF-C versus HF-C, suggesting that the influence of feeding a high fermentable diet on those cellulolytics was likely minimal. The abundance of members of phylum Verrucomicrobia decreased for LF-C versus HF-C. Small abundances of members of this phylum were usu- 


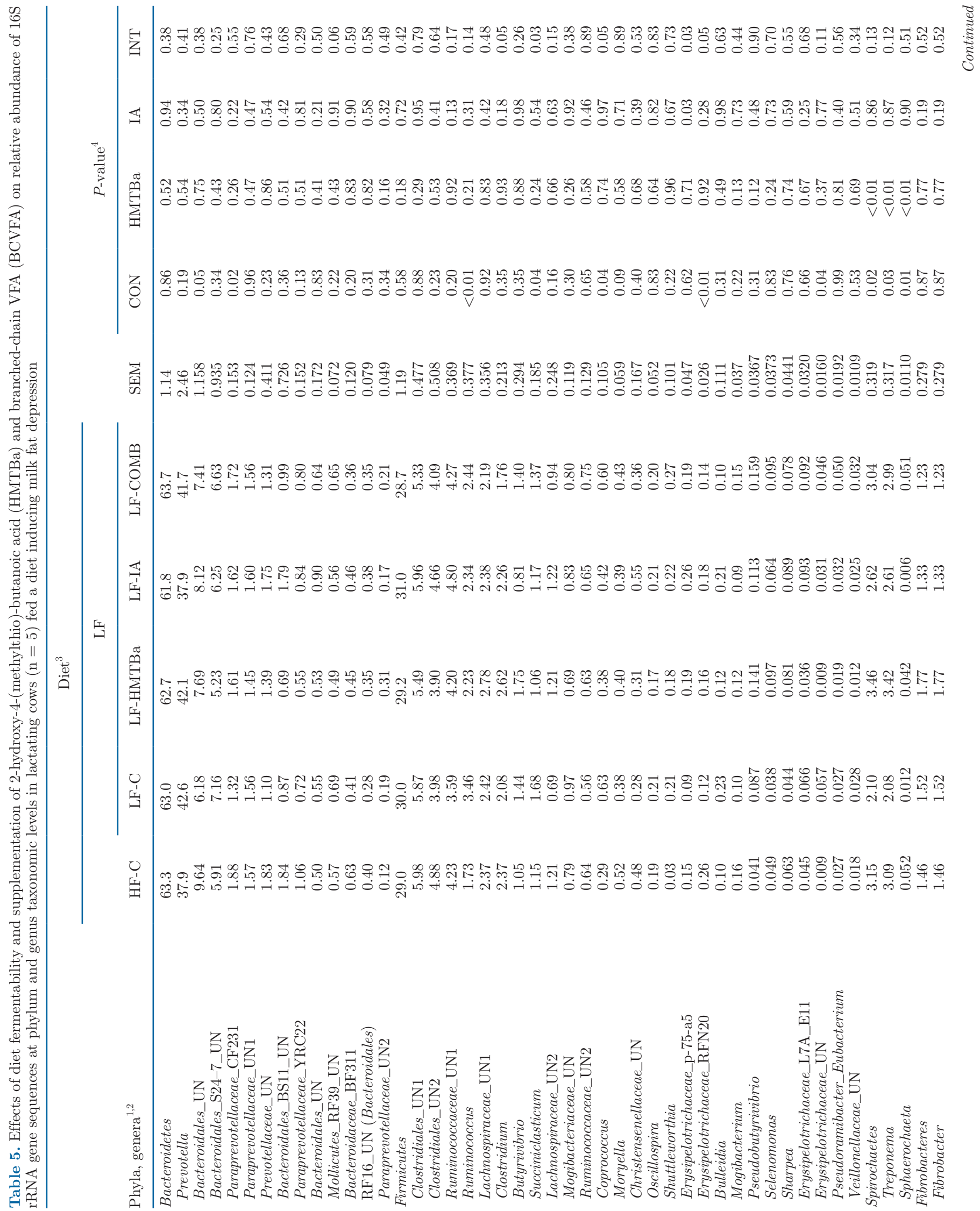




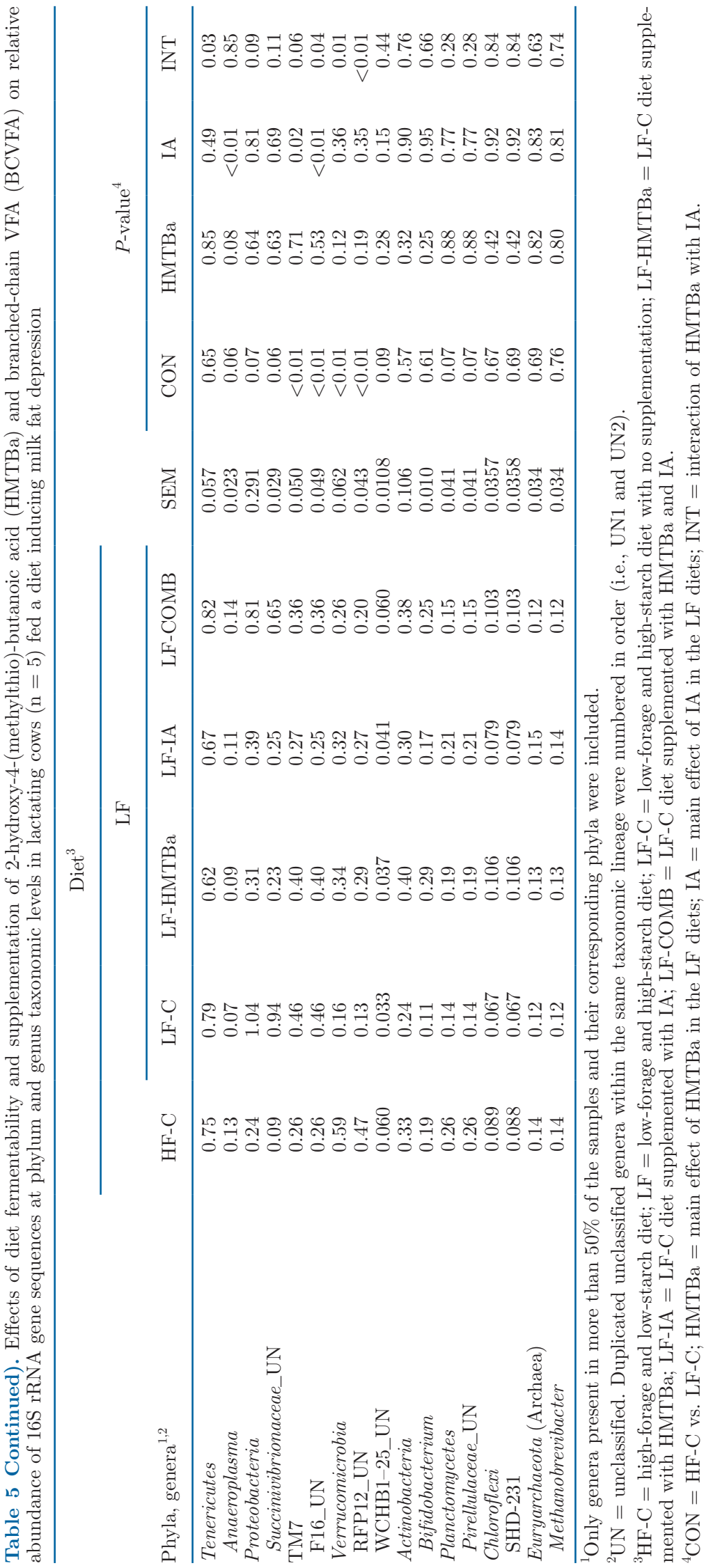


ally observed in the rumen (Deusch et al., 2017), and the role of this phylum is not well understood. However, its potential functional importance in the rumen has been suggested by metaproteomics, because the abundance of verrucomicrobial proteins was higher compared with the corresponding OTU (Deusch et al., 2017). A decrease in phylum Planctomycetes for LF-C versus HF-C was explained by decreased Pirellulaceae_UN at genus level. Members of the family Pirellulaceae have been studied more as soil and marine microorganisms and are known as ammonia oxidizers. The abundance of this microorganism increases as soil $\mathrm{pH}$ increases (Hermans et al., 2016). In the rumen, members of Pirellulaceae were observed to be negatively correlated with ruminal concentration of trans-10 C18 intermediates during biohydrogenation in goats (Dewanckele et al., 2018). However, no differences in the concentrations of trans-10 C18 in the rumen were observed in the current study. The abundance of members of Proteobacteria tended to increase in the rumen for LF-C versus HF$\mathrm{C}$, which is in line with previous studies when a highforage diet is switched to a high-concentrate diet (Fernando et al., 2010; Petri et al., 2013). An increase in the abundance of Succinivibrionaceae_UN mostly explains the increase in this phylum. In the rumen, the family Succinivibrionaceae is common and known to degrade starch and sugars to produce propionate (Santos and Thompson, 2014). In addition, Dewanckele et al. (2018) observed positive correlation between Succinivibrionaceae and ruminal concentration of trans-10 C18:1 in goats. However, ruminal concentrations of trans-10 C18 isomers were not affected in the current study. This lack of response is probably because the PUFA concentrations between LF-C and HF-C were the same, and the changes in Planctomycetes and Proteobacteria occurred due to ruminal $\mathrm{pH}$ and starch concentration and were not involved in lipid metabolism (e.g., biohydrogenation). These results indicate that enhancement of the alternative biohydrogenation pathway producing greater trans-10 $\mathrm{C} 18$ isomers was not the main factor causing moderate MFD for LF-C versus HF-C (Copelin et al., 2021), although the dietary inclusion of PUFA was relatively similar to that found in MFD-inducing diets in previous studies (Ramirez Ramirez et al., 2015; Baldin et al., 2018b). The lack of difference in ruminal trans-10 C18 isomers is also supported by the lack of changes in concentration of $\mathrm{C} 18$ trans-10 isomers in milk for LF-C versus HF-C in our companion study (Copelin et al., 2021). It has been well understood that severe decreases in milk fat with dietary changes are explained the most by the biohydrogenation-induced MFD, and changes in rumen VFA profile (acetate and propionate) are minor factors (Jenkins and Harvatine, 2014). However, the moderate MFD induced by dietary changes is likely explained better by the shift of ruminal VFA profile and bacterial diversity in the current study.

\section{Main Effect of HMTBa Within the LF Diets}

In previous studies (Baldin et al., 2018b; Pitta et al., 2020), supplemental HMTBa alleviated MFD in highproducing cows fed MFD diets. The mode of action for HMTBa to alleviate risk of MFD was successfully explained, at least in part, by reduced perturbations in ruminal microbiota. The study by Pitta et al. (2020) observed differences in Dialister, E11, Lachnospira, Megasphaera, Sharpea, SR1, and F16 between HMTBa and no HMTBa during MFD, but we did not observe changes of those genera. In addition, Pitta et al. (2020) found differences in $\alpha$ - and $\beta$-diversity between HMTBa and no HMTBa, which did not differ in our study. However, in our study, HMTBa increased relative sequence abundance of phylum Spirochaetes, as represented by increased genera Treponema and Sphaerochaeta. As discussed previously, members of the motile noncellulolytic Spirochaetes are generally thought to enhance movement of the nonmotile cellulolytic bacteria into the fiber matrix, allowing close contact with their cell-associated fibrolytic enzymes (Stanton and CanaleParola, 1980; Kudo et al., 1987). Therefore, increased abundances of Treponema and Sphaerochaeta may have had a role in affecting rumen cellulolytic activity and alleviating MFD for HMTBa in this study. In our companion study, however, total-tract digestibility of NDF was only numerically increased (44 vs. $42.2 \% ; P=$ $0.19)$, perhaps because of compensatory hindgut fiber degradation. In addition, increased ratios of acetate to propionate and butyrate in cows fed HMTBa partly support potential increases in ruminal cellulolytic activity with increased members of Spirochaetes, even though the abundances of cellulolytic bacteria were not altered.

Despite the changes in ruminal VFA and the abundance of Spirochaetes, overall changes in the bacterial community were minimal (relative abundances and $\alpha$ - and $\beta$-diversity) for HMTBa. This discrepancy with a previous study by Pitta et al. (2020) is difficult to explain other than dietary and animal variations between studies, experimental designs, and methodological differences in determining bacterial community structure (e.g., 16S rRNA sequencing). However, the degree of MFD that occurred with LF-C was much moderate compared with MFD induced in the study by Pitta et al. (2020). As already discussed, increased trans-10 C18 isomers from alternate biohydrogenation was not the main factor for the moderate MFD observed in this study, but that was likely the main factor in Pitta et al. (2020), according to their changes in trans-10 and 
trans-11 C18:1 in milk. Despite the lack of considerable changes in ruminal bacterial community and diversity in the current study, ruminal concentrations of saturated $\mathrm{FA}$ (C16:0 and C18:0) were greater and those of various $\mathrm{C} 18$ trans and cis FA decreased when HMTBa was fed in our study. In addition, the concentration of linoleic acid was lower for HMTBa, potentially indicating increased biohydrogenation capacity as supported by decreased trans-11 C18:1. Baldin et al. (2018a) examined changes in biohydrogenation intermediates in the rumen following a bolus dose of linoleic acid. Although other intermediates (cis-9,trans-11 C18:2, trans-10,cis-12 $\mathrm{C} 18: 2$, and trans-10 C18:1) peaked at 2 to $3 \mathrm{~h}$ after the dose and became similar to the background level at $6 \mathrm{~h}$ after the dose, trans-11 C18:1 stayed relatively high at $6 \mathrm{~h}$ after the dose. The lower concentration of trans-11 C18:1 at $6 \mathrm{~h}$ after feeding in the current study indicates more active biohydrogenation when HMTBa was provided. One explanation for increased biohydrogenation without major shifts in the relative proportion of bacterial community members could be an increase in mass of rumen bacteria. Indeed, Lee et al. (2015) observed an increase in microbial protein synthesis when HMTBa was fed to cows. However, no changes in microbial protein synthesis in a continuous culture system for HMTBa also were reported by Noftsger et al. (2003) and Fowler et al. (2015).

\section{Main Effect of IA Within the LF Diets}

Molar proportions of isobutyrate, isovalerate, and 2-methylbutyrate were increased when IA was provided, as expected. Further investigation on the interactions for valerate between HMTBa and IA indicates that LF-IA increased $(P=0.02$; data not shown) valerate concentration compared with LF (this increase disappeared for LF-COMB; see further discussion about interactions later). This means that IA supplementation successfully provided additional IA to rumen microbes. However, the increases in their concentrations also indicate that the additional supplies of IA were not likely utilized fully. Increases in ruminal BCVFA concentrations were observed with BCVFA supplementation in dairy calves and cows (Liu et al., 2018a,b) but not when BCVFA were fed to steers (Wang et al., 2012). It is likely that the rumen bacterial need for BCVFA changes under different dietary conditions, which was partly discussed in a review by Firkins et al. (2006). Although IA provided was not fully utilized in the rumen, an increase in $\alpha$-diversity (greater richness of rumen bacterial species) and an increase in the diversity of rumen bacterial functional features (e.g., more various enzymes) were observed for IA. This is in line with results from Liu et al. (2014), who noted that isovalerate supplementation increased various ruminal enzyme activities (cellulase, glucosidase, and amylase) in steers fed a high-forage diet (57\% NDF). In that study, the qPCR copies of cellulolytic bacteria and total bacteria in the rumen increased linearly with increasing isovalerate supplementation. Similar results were observed by Wang et al. (2012) when 2-methylbutyrate was provided to steers fed a high-forage diet $(57 \%$ NDF). We observed a tendency for increased ammonia concentration as the main effect of IA with an interaction between HMTBa and IA. Further investigation of the interaction indicates that ammonia concentration for LF-IA was greater compared with LF-C. Ruminal ammonia concentrations in response to IA are likely related to dietary protein supply. For example, Wang et al. (2018) observed an interaction between 2-methylbutyrate supplementation and dietary protein levels (10 and $13 \%$ on a DM basis) in steers. With the low-protein diet, ruminal ammonia concentration was lower when 2-methylbutyrate was supplemented, but this did not occur with the high-protein diet. It is likely that IA supplementation has less effect on microbial utilization of ammonia when supply of rumen degradable protein is excessive. In the current study, dietary protein concentration was about $16 \%$ (DM basis), which provided sufficient RDP ( $10 \%$ of DM) to cows.

In terms of bacterial community, TM7 was the only phylum that decreased in abundance for IA, as represented by decreased unclassified F16. Increases in p75-a5 and Anaeroplasma for IA were also found. These organisms are in relatively low abundance in the rumen (Jewell et al., 2015; Bainbridge et al., 2016; Liu et al., 2016), and their roles in the rumen are not yet known.

Although few differences in relative abundance of bacterial communities were observed, IA likely had more effects on rumen microbes compared with HMTBa, according to $\alpha$-diversity and the number of functional features. However, the concentrations of linoleic acid and total saturated and unsaturated FA were not altered by IA, suggesting that biohydrogenation was likely unchanged. Supplementation with IA increased C18:1 trans -10 and C18:2 trans-10,cis-12 and decreased C18:2 cis-9,trans-11 concentrations. Although the biohydrogenation capacity did not seem to be altered, IA supplementation apparently increased the alternate route of biohydrogenation. This result was not expected, because we assumed that additional IA supply enhances cellulolytic bacteria, and many cellulolytics have been shown to be capable of biohydrogenation of PUFA (Harfoot and Hazlewood, 1997; Buccioni et al., 2012). We do not know how IA increased the concentrations of trans-10 C18 isomers in the rumen. Although IA increased the concentrations of trans-10 C18 isomers in the rumen, C18 trans-10 isomers in milk were not 
affected (although C18 trans-11 isomers in milk decreased), and IA supplementation actually alleviated MFD, as mediated via increased de novo synthesized FA (Copelin et al., 2021). This may indicate that concentrations of rumen FA at a single time point within a feeding cycling is not reliable to reflect biohydrogenation capacity and flows of FA, or perhaps further postruminal metabolism exists, such as mediated via growth hormone (Wang et al., 2019), in relation to milk fat profile. Further studies are needed to understand the requirement of IA under varying dietary conditions and their effects on ruminal and postruminal FA metabolism.

\section{Interaction of the Main Effects Between HMTBa and IA Within the LF Diets}

According to the patterns of changes in ruminal fermentation, bacterial diversity and community, and FA profile, effects of HMTBa and IA in the rumen existed but were different. However, interactions for some variables indicate associative effects between HMTBa and IA, and therefore caution is needed to understand their combination effects. An interaction for ruminal $\mathrm{NH}_{3}$ occurred because of lack of an additive effect for LF-COMB, although LF-HMTBa and LF-IA increased $\mathrm{NH}_{3}$ concentration compared with LF-C. The effect of increased butyrate and decreased 2-methylbutyrate for LF-HMTBa compared with LF-C disappeared for LF-COMB. In addition, LF-IA increased molar proportion of valerate compared with LF, but this effect did not appear for LF-COMB. Despite the interactions for ruminal fermentation variables, no major interactions for ruminal FA profile were found between HMTBa and IA, which suggests that groups of bacteria that were affected by LF-COMB (i.e., causing interactions) were not associated with ruminal lipid metabolism. Interestingly, any interaction for either $\alpha$-diversity or the number of functional features was not observed, meaning that the effects of IA on rumen bacteria were maintained when provided in combination with HMTBa and the effects of LF-COMB causing the interactions were likely small in the rumen. The interactions for ruminal fermentation variables could have been related to interactions shown for some bacteria between HMTBa and IA. Further investigation of the interactions indicated that associative effects between HMTBa and IA were apparent for phyla TM7 and Verrucomicrobia and genera Succiniclasticum, p-75-a5, RFN20, RF3_UN, RFP12_UN, and F16_UN. As discussed previously, the relative abundances of these groups of bacteria are relatively small in the rumen, and their roles in rumen ecology are not clear. We do not know any biochemical or physiological backgrounds for the interactions between
HMTBa and IA for some ruminal variables and bacterial abundances. As mentioned previously, BCVFA are required nutrients for some rumen microbes, and Met is also an important growth factor for rumen microbes because Met is a methyl donor and the Met cycle between Met and ketomethylthiobutyrate (converted from HMTBa) produces essential metabolites for cell growth and proliferation, such as polyamines (Theiss et al., 2002). Although not characterized in rumen microbes, gut microbes use common aminotransferase enzymes (AraT and BcaT) for transamination of BCAA and Met (Fernández and Zúñiga, 2006); the keto acids could be regenerated to BCAA by the glutamate $/ \alpha$ ketoglutarate couple. Therefore, the metabolism of BCAA and Met are closely associated in cells. Because of the common aminotransferase, either BCVFA or HMTBa may have been imbalanced. More studies are needed to understand the interactive mechanisms of ruminal bacterial community and fermentation between HMTBa and IA.

\section{CONCLUSIONS}

The LF-C diet caused MFD by altering bacterial community and diversity and ruminal fermentation (VFA profile). The alternate biohydrogenation producing trans-10 $\mathrm{C} 18$ isomers was not the main factor causing moderate MFD, although PUFA content was relatively high. Supplementation of HMTBa altered ruminal fermentation and ruminal FA profile but did not change rumen bacterial diversity and community, suggesting that HMTBa supplementation potentially increased the mass of microbes in the rumen and increased ruminal biohydrogenation capacity. Supplementation of IA increased ruminal concentrations of IA, altered rumen bacterial diversity and functional features, and increased ruminal concentrations of trans-10 C18 isomers, suggesting that IA in the rumen affected bacterial function. The interaction between HMTBa and IA was not considerable in the rumen, but interactions occurred, because effects of HMTBa or IA were not additive when HMTBa and IA were provided in combination. More studies are needed to understand the interactive mechanism between HMTBa and IA in the rumen.

\section{ACKNOWLEDGMENTS}

This project was supported by state and federal funds appropriated to the Ohio Agricultural Research and Development Center, The Ohio State University (Wooster, OH), and partially funded by Adisseo (Alpharetta, GA) and Zinpro Corporation (Eden Prairie, MN). The authors thank P. A. Dieter (The Ohio State 
University, Wooster) for assistance with sample collection and laboratory assays, all staff at Krauss Dairy Research Center (Ohio Agricultural Research and Development Center, The Ohio State University, Wooster) for animal care, and staff at the Molecular and Cellular Imaging Center (Ohio Agricultural and Research and Development Center, The Ohio State University, Wooster) for sequencing. The isoacid product used in this study is a product in development at Zinpro Corporation, and it is the intent of Zinpro Corporation to eventually commercialize this product. One of the authors of this paper, M. T. Socha, is an employee of Zinpro Corporation. The authors have not stated any other conflicts of interest.

\section{REFERENCES}

Allison, M. J., M. P. Bryant, and R. N. Doetsch. 1962. Studies on the metabolic function of branched-chain volatile fatty acids, growth factors for ruminococci. I. Incorporation of isovalerate into leucine. J. Bacteriol. 83:523-532. https://doi.org/10.1128/JB.83.3.523-532 .1962 .

AlZahal, O., F. Li, L. L. Guan, N. D. Walker, and B. W. McBride. 2017. Factors influencing ruminal bacterial community diversity and composition and microbial fibrolytic enzyme abundance in lactating dairy cows with a focus on the role of active dry yeast. J. Dairy Sci. 100:4377-4393. https://doi.org/10.3168/jds.2016-11473.

Andries, J. I., F. X. Buysse, D. L. De Brabander, and B. G. Cottyn. 1987. Isoacids in ruminant nutrition: Their role in ruminal and intermediary metabolism and possible influences on performancesA review. Anim. Feed Sci. Technol. 18:169-180. https://doi.org/10 .1016/0377-8401(87)90069-1.

Bainbridge, M. L., L. M. Cersosimo, A. D. Wright, and J. Kraft. 2016. Rumen bacterial communities shift across a lactation in Holstein, Jersey and Holstein $\times$ Jersey dairy cows and correlate to rumen function, bacterial fatty acid composition and production parameters. FEMS Microbiol. Ecol. 92:fiw059. https://doi.org/10.1093/ femsec/fiw059.

Baldin, M., D. E. Rico, M. H. Green, and K. J. Harvatine. 2018a. Technical note: An in vivo method to determine kinetics of unsaturated fatty acid biohydrogenation in the rumen. J. Dairy Sci. 101:4259-4267. https://doi.org/10.3168/jds.2017-13452.

Baldin, M., G. I. Zanton, and K. J. Harvatine. 2018b. Effect of 2-hydroxy-4-(methylthio)butanoate (HMTBa) on risk of biohydrogenation-induced milk fat depression. J. Dairy Sci. 101:376-385. https: //doi.org/10.3168/jds.2017-13446.

Bolyen, E., J. R. Rideout, M. R. Dillon, N. Bokulich, C. C. Abnet, G. A. Al-Ghalith, H. Alexander, E. J. Alm, M. Arumugam, F. Asnicar, Y. Bai, J. E. Bisanz, K. Bittinger, A. Brejnrod, C. J. Brislawn, C. T. Brown, B. J. Callahan, A. M. Caraballo-Rodriguez, J. Chase, E. K. Cope, R. Da Silva, C. Diener, P. C. Dorrestein, G. M. Douglas, D. M. Durall, C. Duvallet, C. F. Edwardson, M. Ernst, M. Estaki, J. Fouquier, J. M. Gauglitz, S. M. Gibbons, D. L. Gibson, A. Gonzalez, K. Gorlick, J. R. Guo, B. Hillmann, S. Holmes, H. Holste, C. Huttenhower, G. A. Huttley, S. Janssen, A. K. Jarmusch, L. J. Jiang, B. D. Kaehler, K. Bin Kang, C. R. Keefe, P. Keim, S. T. Kelley, D. Knights, I. Koester, T. Kosciolek, J. Kreps, M. G. I. Langille, J. Lee, R. Ley, Y. X. Liu, E. Loftfield, C. Lozupone, M. Maher, C. Marotz, B. D. Martin, D. McDonald, L. J. McIver, A. V. Melnik, J. L. Metcalf, S. C. Morgan, J. T. Morton, A. T. Naimey, J. A. Navas-Molina, L. F. Nothias, S. B. Orchanian, T. Pearson, S. L. Peoples, D. Petras, M. L. Preuss, E. Pruesse, L. B. Rasmussen, A. Rivers, M. S. Robeson, P. Rosenthal, N. Segata, M. Shaffer, A. Shiffer, R. Sinha, S. J. Song, J. R. Spear, A. D. Swafford, L. R. Thompson, P. J. Torres, P. Trinh, A. Tripathi, P. J. Turnbaugh, S. Ul-Hasan, J. J. J. vander Hooft, F.
Vargas, Y. Vazquez-Baeza, E. Vogtmann, M. von Hippel, W. Walters, Y. H. Wan, M. X. Wang, J. Warren, K. C. Weber, and C. H. D. Williamso.nWillis, A. D., Z. Z. Xu, J. R. Zaneveld, Y. L. Zhang, Q. Y. Zhu, R. Knight, and J. G. Caporaso. 2019. Reproducible, interactive, scalable and extensible microbiome data science using QIIME 2. Nat. Biotechnol. 37:852-857.

Buccioni, A., M. Decandia, S. Minieri, G. Molle, and A. Cabiddu. 2012. Lipid metabolism in the rumen: New insights on lipolysis and biohydrogenation with an emphasis on the role of endogenous plant factors. Anim. Feed Sci. Technol. 174:1-25. https://doi.org/ 10.1016/j.anifeedsci.2012.02.009.

Callahan, B. J., P. J. Mcmurdie, M. J. Rosen, A. W. Han, A. J. A. Johnson, and S. P. Holmes. 2016. DADA2: High-resolution sample inference from Illumina amplicon data. Nat. Methods 13:581-583. https://doi.org/10.1038/nmeth.3869.

Caporaso, J. G., J. Kuczynski, J. Stombaugh, K. Bittinger, F. D. Bushman, E. K. Costello, N. Fierer, A. G. Pena, J. K. Goodrich, J. I. Gordon, G. A. Huttley, S. T. Kelley, D. Knights, J. E. Koenig, R. E. Ley, C. A. Lozupone, D. McDonald, B. D. Muegge, M. Pirrung, J. Reeder, J. R. Sevinsky, P. J. Turnbaugh, W. A. Walters, J. Widmann, T. Yatsunenko, J. Zaneveld, and R. Knight. 2010. QIIME allows analysis of high-throughput community sequencing data. Nat. Methods 7:335-336. https://doi.org/10.1038/nmeth.f .303.

Chaney, A. L., and E. P. Marbach. 1962. Modified reagents for determination of urea and ammonia. Clin. Chem. 8:130-132.

Copelin, J. E., J. L. Firkins, M. T. Socha, and C. Lee. 2021. Effects of diet fermentability and supplementation of 2-hydroxy4-(methylthio)-butanoic acid and isoacids on milk fat depression: 1. Production, milk fatty acid profile, and nutrient digestibility. J. Dairy Sci. 104:1591-1603. https://doi.org/10.3168/jds.2020-18949

Dehority, B. A., H. W. Scott, and P. Kowaluk. 1967. Volatile fatty acid requirements of cellulolytic rumen bacteria. J. Bacteriol. 94:537543. https://doi.org/10.1128/JB.94.3.537-543.1967.

Deusch, S., A. Camarinha-Silva, J. Conrad, U. Beifuss, M. Rodehutscord, and J. Seifert. 2017. A structural and functional elucidation of the rumen microbiome influenced by various diets and microenvironments. Front. Microbiol. 8:1605. https://doi.org/10 .3389 /fmicb.2017.01605.

Dewanckele, L., P. G. Toral, B. Vlaeminck, and V. Fievez. 2020. Invited review: Role of rumen biohydrogenation intermediates and rumen microbes in diet-induced milk fat depression: An update. J. Dairy Sci. 103:7655-7681. https://doi.org/10.3168/jds.2019-17662.

Dewanckele, L., B. Vlaeminck, E. Hernandez-Sanabria, A. Ruiz-Gonzalez, S. Debruyne, J. Jeyanathan, and V. Fievez. 2018. Rumen biohydrogenation and microbial community changes upon early life supplementation of 22:6n-3 enriched microalgae to goats. Front. Microbiol. 9:573. https://doi.org/10.3389/fmicb.2018.00573.

Erwin, E. S., G. J. Marco, and E. M. Emery. 1961. Volatile fatty acid analysis of blood and rumen fluid by gas chromatography. J. Dairy Sci. 44:1768-1771. https://doi.org/10.3168/jds.S0022 -0302(61)89956-6.

Fernández, M., and M. Zúñiga. 2006. Amino acid catabolic pathways of lactic acid bacteria. Crit. Rev. Microbiol. 32:155-183. https:/ doi.org/10.1080/10408410600880643.

Fernando, S. C., H. T. Purvis 2nd, F. Z. Najar, L. O. Sukharnikov, C. R. Krehbiel, T. G. Nagaraja, B. A. Roe, and U. Desilva. 2010. Rumen microbial population dynamics during adaptation to a high-grain diet. Appl. Environ. Microbiol. 76:7482-7490. https:// doi.org/10.1128/AEM.00388-10.

Firkins, J. L., A. N. Hristov, M. B. Hall, G. A. Varga, and N. R. St-Pierre. 2006. Integration of ruminal metabolism in dairy cattle. J. Dairy Sci. 89:E31-E51. https://doi.org/10.3168/jds.S0022 -0302(06)72362-1.

Fowler, C. M., J. E. Plank, E. Devillard, B. J. Bequette, and J. L. Firkins. 2015. Assessing the ruminal action of the isopropyl ester of 2-hydroxy-4-(methylthio) butanoic acid in continuous and batch cultures of mixed ruminal microbes. J. Dairy Sci. 98:1167-1177. https://doi.org/10.3168/jds.2014-8692.

Fuentes, M. C., S. Calsamiglia, P. W. Cardozo, and B. Vlaeminck. 2009. Effect of $\mathrm{pH}$ and level of concentrate in the diet on the pro- 
duction of biohydrogenation intermediates in a dual-flow continuous culture. J. Dairy Sci. 92:4456-4466. https://doi.org/10.3168/ jds.2008-1722.

Hackmann, T. J., and J. L. Firkins. 2015. Maximizing efficiency of rumen microbial protein production. Front. Microbiol. 6. https://doi .org/10.3389/fmicb.2015.00465.

Hammer, Ø., D. A. Harper, and P. D. Ryan. 2001. PAST: Paleontological statistics software package for education and data analysis. Palaeontol. Electronica 4:9.

Harfoot, G. C., and G. P. Hazlewood. 1997. Lipid metabolism in the rumen. Pages 382-426 in The Rumen Microbial Ecosystem. P. N. Hobson and C. S. Stewart, ed. Blackie Academic and Professional, London, UK.

Hermans, S. M., H. L. Buckley, B. S. Case, F. Curran-Cournane, M. Taylor, and G. Lear. 2016. Bacteria as emerging indicators of soil condition. Appl. Environ. Microbiol. 83:e2826-16. https://doi .org/10.1128/AEM.02826-16.

Jenkins, T. C. 2010. Technical note: Common analytical errors yielding inaccurate results during analysis of fatty acids in feed and digesta samples. J. Dairy Sci. 93:1170-1174.

Jenkins, T. C., and K. J. Harvatine. 2014. Lipid feeding and milk fat depression. Vet. Clin. North Am. Food Anim. Pract. 30:623-642. https://doi.org/10.1016/j.cvfa.2014.07.006.

Jewell, K. A., C. A. McCormick, C. L. Odt, P. J. Weimer, and G. Suen. 2015. Ruminal bacterial community composition in dairy cows is dynamic over the course of two lactations and correlates with feed efficiency. Appl. Environ. Microbiol. 81:4697-4710. https://doi.org/10.1128/AEM.00720-15.

Klevenhusen, F., R. M. Petri, M. T. Kleefisch, R. Khiaosa-Ard, B. U. Metzler-Zebeli, and Q. Zebeli. 2017. Changes in fibre-adherent and fluid-associated microbial communities and fermentation profiles in the rumen of cattle fed diets differing in hay quality and concentrate amount. FEMS Microbiol. Ecol. 93:fix100. https://doi .org/10.1093/femsec/fix100.

Kudo, H., K. J. Cheng, and J. W. Costerton. 1987. Interactions between Treponema bryantii and cellulolytic bacteria in the in vitro degradation of straw cellulose. Can. J. Microbiol. 33:244-248. https://doi.org/10.1139/m87-041.

Lee, C., J. Oh, A. N. Hristov, K. Harvatine, M. Vazquez-Anon, and G. I. Zanton. 2015. Effect of 2-hydroxy-4-methylthio-butanoic acid on ruminal fermentation, bacterial distribution, digestibility, and performance of lactating dairy cows. J. Dairy Sci. 98:1234-1247. https://doi.org/10.3168/jds.2014-8904.

Li, M., G. B. Penner, E. Hernandez-Sanabria, M. Oba, and L. L. Guan. 2009. Effects of sampling location and time, and host animal on assessment of bacterial diversity and fermentation parameters in the bovine rumen. J. Appl. Microbiol. 107:1924-1934. https://doi .org/10.1111/j.1365-2672.2009.04376.x.

Liu, J., M. Zhang, C. Xue, W. Zhu, and S. Mao. 2016. Characterization and comparison of the temporal dynamics of ruminal bacterial microbiota colonizing rice straw and alfalfa hay within ruminants. J. Dairy Sci. 99:9668-9681. https://doi.org/10.3168/jds .2016-11398.

Liu, Q., C. Wang, G. Guo, W. J. Huo, S. L. Zhang, C. X. Pei, Y. L. Zhang, and H. Wang. 2018a. Effects of branched-chain volatile fatty acids on lactation performance and mRNA expression of genes related to fatty acid synthesis in mammary gland of dairy cows. Animal 12:2071-2079. https://doi.org/10.1017/ S1751731118000113.

Liu, Q., C. Wang, G. Guo, W. J. Huo, Y. L. Zhang, C. X. Pei, S. L. Zhang, and H. Wang. 2018b. Effects of branched-chain volatile fatty acids supplementation on growth performance, ruminal fermentation, nutrient digestibility, hepatic lipid content and gene expression of dairy calves. Anim. Feed Sci. Technol. 237:27-34. https://doi.org/10.1016/j.anifeedsci.2018.01.006.

Liu, Q., C. Wang, C. X. Pei, H. Y. Li, Y. X. Wang, S. L. Zhang, Y. L. Zhang, J. P. He, H. Wang, W. Z. Yang, Y. S. Bai, Z. G. Shi, and X. N. Liu. 2014. Effects of isovalerate supplementation on microbial status and rumen enzyme profile in steers fed on corn stover based diet. Livest. Sci. 161:60-68. https://doi.org/10.1016/ j.livsci.2013.12.034.
Maczulak, A. E., B. A. Dehority, and D. L. Palmquist. 1981. Effects of long-chain fatty acids on growth of rumen bacteria. Appl. Environ. Microbiol. 42:856-862. https://doi.org/10.1128/AEM.42.5.856-862 .1981.

Martin, M. 2011. Cutadapt removes adapter sequences from highthroughput sequencing reads. EMBnet. J. 17:10-12. https://doi .org/10.14806/ej.17.1.200.

Noftsger, S. M., N. R. St-Pierre, S. K. R. Karnati, and J. L. Firkins. 2003. Effects of 2-hydroxy-4-(methylthio) butanoic acid (HMB) on microbial growth in continuous culture. J. Dairy Sci. 86:26292636. https://doi.org/10.3168/jds.S0022-0302(03)73858-2.

NRC. 2001. Nutrient Requirements of Dairy Cattle. 7th rev. ed. Natl. Acad. Sci., Washington, DC.

Peirce-Sandner, S. B., A. M. Papas, J. A. Rogers, T. F. Sweeney, K. A. Cummins, H. R. Conrad, and L. D. Muller. 1985. Supplementation of dairy-cow diets with ammonium-salts of volatile fatty-acids. J. Dairy Sci. 68:2895-2907. https://doi.org/10.3168/jds.S0022 $-0302(85) 81183-8$.

Petri, R. M., T. Schwaiger, G. B. Penner, K. A. Beauchemin, R. J. Forster, J. J. McKinnon, and T. A. McAllister. 2013. Characterization of the core rumen microbiome in cattle during transition from forage to concentrate as well as during and after an acidotic challenge. PLoS One 8:e83424. https://doi.org/10.1371/journal .pone.0083424.

Piao, H., M. Lachman, S. Malfatti, A. Sczyrba, B. Knierim, M. Auer, S. G. Tringe, R. I. Mackie, C. J. Yeoman, and M. Hess. 2014. Temporal dynamics of fibrolytic and methanogenic rumen microorganisms during in situ incubation of switchgrass determined by 16S rRNA gene profiling. Front. Microbiol. 5:307. https://doi.org/ 10.3389/fmicb.2014.00307.

Pitta, D. W., N. Indugu, B. Vecchiarelli, M. Hennessy, M. Baldin, and K. J. Harvatine. 2020. Effect of 2-hydroxy-4-(methylthio) butanoate (HMTBa) supplementation on rumen bacterial populations in dairy cows when exposed to diets with risk for milk fat depression. J. Dairy Sci. 103:2718-2730. https://doi.org/10.3168/ jds.2019-17389.

Quast, C., E. Pruesse, P. Yilmaz, J. Gerken, T. Schweer, P. Yarza, J. Peplies, and F. O. Glöckner. 2013. The SILVA ribosomal RNA gene database project: improved data processing and web-based tools. Nucleic Acids Res. 41(D1):D590-D596. https://doi.org/10 $.1093 / \mathrm{nar} / \mathrm{gks} 1219$.

Ramirez Ramirez, H. A., E. Castillo Lopez, K. J. Harvatine, and P. J. Kononoff. 2015. Fat and starch as additive risk factors for milk fat depression in dairy diets containing corn dried distillers grains with solubles. J. Dairy Sci. 98:1903-1914. https://doi.org/ 10.3168/jds.2014-8528.

Rico, D. E., and K. J. Harvatine. 2013. Induction of and recovery from milk fat depression occurs progressively in dairy cows switched between diets that differ in fiber and oil concentration. J. Dairy Sci. 96:6621-6630. https://doi.org/10.3168/jds.2013-6820.

Rico, D. E., A. W. Holloway, and K. J. Harvatine. 2014. Effect of monensin on recovery from diet-induced milk fat depression. J. Dairy Sci. 97:2376-2386. https://doi.org/10.3168/jds.2013-7486.

Roman-Garcia, Y., R. R. White, and J. L. Firkins. 2016. Meta-analysis of postruminal microbial nitrogen flows in dairy cattle. I. Derivation of equations. J. Dairy Sci. 99:7918-7931. https://doi.org/10 .3168/jds.2015-10661.

Sánchez-Duarte, J. I., K. F. Kalscheur, D. P. Casper, and A. D. Garcia. 2019. Performance of dairy cows fed diets formulated at 2 starch concentrations with either canola meal or soybean meal as the protein supplement. J. Dairy Sci. 102:7970-7979. https://doi .org/10.3168/jds.2018-15760.

Santos, E., and F. Thompson. 2014. The family Succinivibrionaceae. Pages 639-648 in The Prokaryotes. M. Dworkin, S. Falkow, E. Rosenberg, K. H. Schleifer, E. Stackebrandt, ed. Springer, Heidelberg, Germany.

Stanton, T. B., and E. Canale-Parola. 1980. Treponema bryantii sp. nov., a rumen spirochete that interacts with cellulolytic bacteria. Arch. Microbiol. 127:145-156. https://doi.org/10.1007/ BF00428018. 
Theiss, C., P. Bohley, and J. Voigt. 2002. Regulation by polyamines of ornithine decarboxylase activity and cell division in the unicellular green alga Chlamydomonas reinhardtii. Plant Physiol. 128:14701479. https://doi.org/10.1104/pp.010896.

van Lingen, H. J., J. E. Edwards, J. D. Vaidya, S. van Gastelen, E. Saccenti, B. van den Bogert, A. Bannink, H. Smidt, C. M. Plugge, and J. Dijkstra. 2017. Diurnal dynamics of gaseous and dissolved metabolites and microbiota composition in the bovine rumen. Front. Microbiol. 8:425. https://doi.org/10.3389/fmicb .2017 .00425 .

Wang, C., Q. Liu, G. Guo, W. J. Huo, C. X. Pei, S. L. Zhang, and W. Z. Yang. 2018. Effects of dietary protein levels and 2-methylbutyrate on ruminal fermentation, nutrient degradability, bacterial populations and urinary purine derivatives in Simmental steers. J. Anim. Physiol. Anim. Nutr. (Berl.) 102:611-619. https://doi.org/ 10.1111/jpn.12797.

Wang, C., Q. Liu, G. Guo, W. J. Huo, Y. L. Zhang, C. X. Pei, and S. L. Zhang. 2019. Effects of rumen-protected folic acid and branched-chain volatile fatty acids supplementation on lactation performance, ruminal fermentation, nutrient digestion and blood metabolites in dairy cows. Anim. Feed Sci. Technol. 247:157-165. https://doi.org/10.1016/j.anifeedsci.2018.11.015.

Wang, C., Q. Liu, C. X. Pei, H. Y. Li, Y. X. Wang, H. Wang, Y. S. Bai, Z. G. Shi, X. N. Liu, and P. Li. 2012. Effects of 2-methylbutyrate on rumen fermentation, ruminal enzyme activities, urinary excretion of purine derivatives and feed digestibility in steers. Livest. Sci. 145:160-166. https://doi.org/10.1016/j.livsci.2012.01.013.

$\mathrm{Yu}$, Z., and M. Morrison. 2004. Improved extraction of PCR-quality community DNA from digesta and fecal samples. Biotechniques 36:808-812. https://doi.org/10.2144/04365ST04.

Zanton, G. I., G. R. Bowman, M. Vazquez-Anon, and L. M. Rode 2014. Meta-analysis of lactation performance in dairy cows receiving supplemental dietary methionine sources or postruminal infusion of methionine. J. Dairy Sci. 97:7085-7101. https://doi.org/10 $.3168 /$ jds.2014-8220.

\section{ORCIDS}

C. Lee (ㄱ https://orcid.org/0000-0002-4522-1232

J. E. Copelin (ํ) https://orcid.org/0000-0003-0549-8189

T. Park (으 https://orcid.org/0000-0002-4480-4524

K. E. Mitchell @ https://orcid.org/0000-0002-9769-3960

J. L. Firkins @ https://orcid.org/0000-0003-3518-1940

M. T. Socha (๑ https://orcid.org/0000-0002-0227-6591

D. Luchini ๑ https://orcid.org/0000-0003-2096-0984 